Case Report

\title{
Efficacy of Cyclosporine in the Induction and Maintenance of Remission in a Systemic Lupus Erythematosus Patient Presenting with Macrophage-Activating Syndrome
}

\author{
Franchesca Cruz-Pérez, Salvador Vilá (D), Grissel Ríos, and Luis M. Vilá \\ Division of Rheumatology, Department of Medicine, University of Puerto Rico Medical Sciences Campus, San Juan, PR, USA \\ Correspondence should be addressed to Salvador Vilá; salvador.vila@upr.edu and Luis M. Vilá; luis.vila2@upr.edu
}

Received 31 August 2017; Revised 24 November 2017; Accepted 3 December 2017; Published 15 January 2018

Academic Editor: Tsai-Ching Hsu

Copyright ( $\odot 2018$ Franchesca Cruz-Pérez et al. This is an open access article distributed under the Creative Commons Attribution License, which permits unrestricted use, distribution, and reproduction in any medium, provided the original work is properly cited.

\begin{abstract}
Macrophage-activating syndrome (MAS) is a rare condition characterized by dysfunctional macrophage activation leading to overproduction of cytokines and phagocytosis of erythrocytes, leukocytes, and platelets. MAS is associated with infectious diseases, malignancies, and autoimmune rheumatic disorders. Herein, we present a 22-year-old Hispanic woman with SLE who was hospitalized because of a three-week history of fever, fatigue, polyarthralgia, nausea, and abdominal pain. Initial laboratories showed severe pancytopenia with marked elevation of liver enzymes and ferritin levels. Bone marrow biopsy revealed macrophages with engulfed erythrocytes consistent with MAS. The patient was treated with high-dose corticosteroids, intravenous immunoglobulins, and cyclosporine $3 \mathrm{mg} / \mathrm{kg} /$ day. She had a remarkable clinical response to this therapy. She was continued on cyclosporine, and prednisone dose was gradually decreased to $7.5 \mathrm{mg}$ daily without experiencing recurrent disease. She remained in full clinical remission for 12 months. Our case, together with other reports, suggests that combination therapy with corticosteroids, immunoglobulins, and cyclosporine appears to be effective for patients with SLE-associated MAS. Furthermore, cyclosporine seems to be a good drug for maintenance of remission.
\end{abstract}

\section{Introduction}

Macrophage-activating syndrome (MAS) is an uncommon and life-threatening complication of infectious diseases, malignancies, and rheumatic diseases that results from uncontrolled production of proinflammatory cytokines leading to overactivation of $\mathrm{T}$ lymphocytes and macrophages $[1,2]$. MAS has been reported in patients with various rheumatic diseases, such as systemic juvenile idiopathic arthritis (sJIA), adult-onset Still's disease, dermatomyositis, and systemic lupus erythematosus (SLE) [1]. SLE-associated MAS is a rare complication that usually occurs in young adults with high lupus activity [1-3]. Women are more affected than men [2-4]. Patients commonly present with fever, fatigue, arthralgia, pancytopenia, elevated liver enzymes, hypertriglyceridemia, hyperferritinemia, and the presence of serological markers related to SLE activity such as elevated anti-dsDNA antibodies and C3 and C4 hypocomplementemia [1-3]. High-dose corticosteroids, cyclophosphamide, cyclosporine, intravenous (IV) immunoglobulins, and etoposide have been used for SLEassociated MAS [3-7]. However, there are no established treatment guidelines regarding the induction and maintenance of remission for these patients. Herein, we report a Hispanic SLE patient with MAS who was treated with high-dose corticosteroids, immunoglobulins, and cyclosporine. She had a remarkable response to this therapy without adverse events and has remained in clinical remission for one year.

\section{Case Presentation}

A 22-year-old Puerto Rican woman with SLE was hospitalized to our institution in August 2016 because of a threeweek history of fever, chills, polyarthralgia, anorexia, nausea, and marked pancytopenia. Seven years before admission, she was diagnosed with SLE manifested by fatigue, anorexia, anemia, leukopenia, thrombocytopenia, positive antinuclear 
TABLE 1: Results of selected blood tests before and after cyclosporine treatment.

\begin{tabular}{|c|c|c|c|c|c|}
\hline Laboratory test & $\begin{array}{l}\text { Two weeks prior to } \\
\text { admission }\end{array}$ & $\begin{array}{c}\text { On } \\
\text { admission }\end{array}$ & $\begin{array}{l}\text { One day after } \\
\text { admission }\end{array}$ & $\begin{array}{c}\text { Five days after cyclosporine } \\
\text { therapy }\end{array}$ & $\begin{array}{c}\text { At } \\
\text { discharge }\end{array}$ \\
\hline WBC $\left(10^{9} / \mathrm{L}\right)$ & 3.03 & 1.4 & 0.57 & 14.30 & 17.1 \\
\hline Hemoglobin (g/dL) & 7.7 & 9.6 & 7.8 & 10.1 & 10.1 \\
\hline Platelet $\left(10^{9} / \mathrm{L}\right)$ & 216 & 51 & 85 & 68 & 83 \\
\hline AST (U/L) & 138 & 451 & - & 38 & 20 \\
\hline $\operatorname{ALT}(\mathrm{U} / \mathrm{L})$ & 73 & 138 & - & 58 & 24 \\
\hline ESR $(\mathrm{mm} / \mathrm{hr})$ & 56 & 70 & 53 & - & - \\
\hline Ferritin $(\mathrm{ng} / \mathrm{mL})$ & 1,290 & 5,602 & - & 3,960 & 802 \\
\hline $\begin{array}{l}\text { Triglycerides } \\
(\mathrm{mg} / \mathrm{dL})\end{array}$ & 122 & 211 & - & - & 150 \\
\hline
\end{tabular}

WBC: white blood cell; AST: aspartate aminotransferase; ALT: alanine aminotransferase; ESR: erythrocyte sedimentation rate (by Westergren).

antibodies (ANAs), elevated anti-dsDNA antibodies, positive anti-RNP antibodies, and hypocomplementemia (C3 and C4). Initially, she was treated with corticosteroids, hydroxychloroquine, and mycophenolate mofetil having a good clinical response. However, she had poor adherence to these medications and self-discontinued her treatment after one year of therapy.

Two weeks prior to hospitalization at our institution, she was admitted to a community hospital due to high-grade fever $\left(40.1^{\circ} \mathrm{C}\right)$, nausea, pancytopenia, and elevated liver enzymes, erythrocyte sedimentation rate (ESR), and ferritin levels. Anti-nuclear antibodies (ANAs) were positive at a titer of 1 : 1280 with a homogeneous pattern. Serum complements levels were normal. Blood cultures were negative, as well as tests for hepatitis $\mathrm{B}$ and $\mathrm{C}$, human immunodeficiency virus, varicella-zoster virus IgM, herpes simplex virus IgM, cytomegalovirus IgM, and Epstein-Barr virus IgM. She was treated with methylprednisolone $60 \mathrm{mg}$ IV daily and broad-spectrum antibiotics including vancomycin and cefepime. Also, fluconazole and acyclovir were added. The hospitalization was complicated with ventricular fibrillation which responded to nonsynchronized cardioversion. She had partial clinical improvement to this therapy and was discharged home, but three days later, she developed worsening of fever and malaise associated with abdominal pain, nausea, and diarrhea.

Upon admission to our institution, she appeared acutely ill. Vital signs showed temperature of $39.5^{\circ} \mathrm{C}$, heart rate of 110 beats per minute, blood pressure of $120 / 65 \mathrm{mmHg}$, and respiratory rate of 18 per minute. Physical examination disclosed right upper quadrant abdominal pain without rebound tenderness or organomegaly. Bowel sounds were normal. She had symmetric polyarthritis involving the hands, wrists, and knees. She had petechial lesions on lower extremities and muscle wasting of upper and lower extremities. She had diffuse hair loss. No nasal or oral ulcers were observed. The rest of the physical exam was unremarkable.

Table 1 shows the laboratories tests during the course of disease. Initially, she presented with leukopenia and anemia that worsened within 24 hours and thrombocytopenia. A peripheral smear revealed poikilocytosis, macrocytosis, anisocytosis, and ovalocytes. No schistocytes were seen. The reticulocyte count was normal at $1.6 \%$. Alanine and aspartate aminotransferase, triglycerides, and ferritin levels were elevated as well as the erythrocyte sedimentation rate. Amylase and lipase levels were negative. Her renal function and urinalysis were within normal limits. Serum C3 complement levels were low at $70 \mathrm{mg} / \mathrm{dL}$. Antinuclear, anti-ribonucleoprotein $(97.4 \mathrm{U} / \mathrm{mL})$ and anti-Ro antibodies ( $>100 \mathrm{U} / \mathrm{mL})$ were elevated. AntidsDNA, anti-Smith, anti-La, and anti-citrullinated peptide antibody levels were negative. Rheumatoid factor was negative. Workup for herpes simplex virus IgM, cytomegalovirus IgM/IgG, and Epstein-Barr virus IgM and Histoplasma urine antigen, Aspergillus antigen, and Legionella urine antigen was negative. The tuberculin test and blood, urine, and sputum cultures were negative. Chest radiograph, electrocardiogram, and echocardiogram showed no abnormalities. Abdominal pelvic computer tomography disclosed an enlarged liver measuring $20.4 \mathrm{~cm}$ with fatty infiltration. Broad-spectrum antibiotics and antifungal treatment were started without improvement. Bone marrow biopsy revealed macrophages with engulfed erythrocytes consistent with MAS.

The patient was treated with cyclosporine $3 \mathrm{mg} / \mathrm{kg} /$ day and methylprednisolone $500 \mathrm{mg}$ IV every day for 3 days, followed by $2 \mathrm{mg} / \mathrm{kg} /$ day IV every day. Also, she received IV immunoglobulins $20 \mathrm{~g}$ daily for 5 days. One day after initiating treatment, fever subsided. Five days after initiation of treatment, WBC count and hemoglobin levels continued to increase and liver enzymes returned to normal limits.

Upon discharge, WBC count, hemoglobin levels, platelet count, and ferritin levels continued to normalize. She was discharged on prednisone of $60 \mathrm{mg}$ daily and cyclosporine $125 \mathrm{mg}$ orally daily. She was continued on cyclosporine (3 $\mathrm{mg} / \mathrm{kg} /$ day), and prednisone was gradually tapered down to $7.5 \mathrm{mg}$ daily. After 12 months of follow-up, the patient remained in complete clinical remission of her MAS with normal WBC, hemoglobin, platelet count, liver enzymes, and ferritin levels. Also, she has not presented clinical manifestations of active SLE.

\section{Discussion}

We describe a Hispanic woman with SLE-associated MAS who was effectively treated with high-dose corticosteroids, 
IV immunoglobulins, and cyclosporine. After one year of follow-up, she has remained in complete clinical remission of both her SLE and MAS. Although the mainstay of treatment of SLE-associated MAS consists of high-dose corticosteroid therapy, the optimal dose, combination with other immunosuppressive drugs, or treatment duration has not been clearly established [2-4, 8-10]. Moreover, no treatment guidelines for refractory cases have been proposed.

Our patient fulfilled the 2016 Classification Criteria for Macrophage Activation Syndrome Complicating Systemic Juvenile Idiopathic Arthritis (criteria met: ferritin $>684 \mathrm{ng} / \mathrm{mL}$, platelet count $\leq 181 \times 10^{9} / \mathrm{L}$, AST $>48$, and triglycerides $>156 \mathrm{mg} / \mathrm{dL}$ ) [11]. Although these classification criteria were validated for patients with sJIA, recent studies have shown that this classification is useful to identify MAS in patients with adult-onset Still's disease and SLE [12, 13]. In addition, our patient met the Systemic Lupus International Collaborating Clinics (SLICC) classification criteria for SLE (criteria met: leukocyte count $<4,000 / \mathrm{mL}$, platelet count $<100 \times 10^{9} / \mathrm{L}$, positive ANA, elevated anti-dsDNA antibodies, and C3 and C4 hypocomplementemia) [14].

Based on previous reports, we used combination of highdose corticosteroids, IV immunoglobulins, and cyclosporine as the induction therapy for our patient. In a case series of 103 episodes of MAS in 89 patients with SLE, the majority were initially treated with high-dose IV methylprednisolone [6]. Thirty-two episodes that were refractory to the corticosteroids required other immunosuppressive treatments. Cyclophosphamide, etoposide, and cyclosporine were most commonly used as second- and third-line therapy. Three episodes were treated with cyclosporine with favorable outcomes without serious side effects after two years of follow-up. Similarly, Liu et al. reported 32 patients with SLEassociated MAS treated with IV pulse corticosteroid therapy alone or in combination with other immunosuppressive agents including cyclosporine (43.8\%), cyclophosphamide (28.1\%), or etoposide (21.9\%), among others [7]. Cyclosporine was given in combination with cyclophosphamide or etoposide in nearly $25 \%$ of patients. IV immunoglobulin therapy was used in $47.9 \%$ of patients. This study reported the death of four patients; three were due to severe infections and one died of multiple organ failure as a consequence of MAS. Additionally, Ravelli et al. described a lupus pediatric patient with MAS treated with cyclosporine after failing several immunosuppressive treatments including high-dose intravenous corticosteroids, IV immunoglobulins, and plasma exchange therapy [5]. This patient experienced a rapid and full recovery without reported side effects. Besides SLE, cyclosporine has shown to be effective for other rheumatic diseases associated with MAS such as sJIA [15, 16]. Minoia et al. described 213 patients with sJIA complicated with MAS in which cyclosporine was the most commonly used drug for those refractory to corticosteroids [15]. In another study, Boom et al. reported that cyclosporine, alone or in combination with other immunosuppressive drugs, was effective to induce remission in the majority of patients with sJIA-associated MAS [16]. On the other hand, the use of biologic agents including infliximab, tocilizumab, anakinra, and canakinumab in patients with MAS is still controversial as data confirming their efficacy are limited and needs further investigation [17, 18].

The pathogenesis in SLE-associated MAS is not well understood. However, it has been proposed that autoantibodies mediate phagocytosis of hematopoietic cells. In addition, the deposition of immune complexes on the bone marrow and oversecretion of cytokines by uncontrolled T-cell activation stimulate the uncontrolled phagocytosis $[8,9,19]$. Consistent with these hypotheses, SLE-associated MAS is associated with higher clinical and serological disease activity and with renal involvement $[3,4,6,7]$.

It can be argued that the prompt clinical response observed in our patient was attributable to corticosteroid and immunoglobulin therapy and not to cyclosporine. However, a study conducted in healthy volunteers and transplant recipients showed marked suppression of interleukin 2, interferon-gamma, and granulocyte-macrophage colonystimulating factor after only two hours of cyclosporine ingestion [20]. Additionally, this calcineurin inhibitor suppresses the production of TNF- $\alpha$, IL-1, and IL-6 [21, 22]. Therefore, it is expected that cyclosporine would be effective in the treatment of SLE-associated MAS in which T-cells have a central pathogenic role. Nonetheless, cyclosporine use is limited in the SLE general management because of its side effects which include nephrotoxicity, severe hypertension, and hyperlipidemia [23]. These side effects are usually dose-related. Our patient was treated with low-dose cyclosporine ( $3 \mathrm{mg} / \mathrm{kg} / \mathrm{day})$ for 12 months without adverse events. On the other hand, tacrolimus, which is another calcineurin inhibitor, is more widely used for SLE than cyclosporine, particularly for those complicated with lupus nephritis $[24,25]$. However, it is unknown if tacrolimus would also be helpful for SLE-associated MAS.

In summary, we report a woman with SLE-associated MAS who responded well to combination therapy with corticosteroids, IV immunoglobulins, and cyclosporine without adverse events. Furthermore, cyclosporine seems to be a good agent for maintenance of remission, as our patient did not experience any exacerbation even after decreasing prednisone to $7.5 \mathrm{mg}$ daily. Our case, together with other reports, reaffirms the importance of early recognition and aggressive treatment for patients with SLE-associated MAS.

\section{Conflicts of Interest}

The authors declare that they have no conflicts of interest.

\section{References}

[1] S. Kumakura and Y. Murakawa, "Clinical characteristics and treatment outcomes of autoimmune-associated hemophagocytic syndrome in adults," Arthritis \& Rheumatology, vol. 66, no. 8, pp. 2297-2307, 2014.

[2] O. Lambotte, M. Khellaf, H. Harmouche et al., "Characteristics and long-term outcome of 15 episodes of systemic lupus erythematosus associated hemophagocytic syndrome," Medicine, vol. 85, no. 3, pp. 169-182, 2006.

[3] N. Jiang, M. T. Li, D. Wu, and X. F. Zeng, "The clinical characteristics of macrophage activation syndrome secondary 
to systemic lupus erythematosus," Zhonghua Nei Ke Za Zhi, vol. 55 , no. 11, pp. $840-844,2016$.

[4] J. M. Kim, S. K. Kwok, J. H. Ju, H. Y. Kim, and S. H. Park, "Reactive hemophagocytic syndrome in adult Korean patients with systemic lupus erythematosus: a case-control study and literature review," Journal of Rheumatology, vol. 39, no. 1, pp. 86-93, 2012.

[5] A. Ravelli, S. Viola, F. De Benedetti, S. Magni-Manzoni, C. Tzialla, and A. Martini, "Dramatic efficacy of cyclosporine A in macrophage activation syndrome," Clinical and Experimental Rheumatology, vol. 19, no. 1, p. 108, 2001.

[6] P. E. Gavand, I. Serio, L. Arnaud et al., "Clinical spectrum and therapeutic management of systemic lupus erythematosusassociated macrophage activation syndrome: a study of 103 episodes in 89 adult patients," Autoimmunity Reviews, vol. 16, no. 7, pp. 743-749, 2017.

[7] A. C. Liu, Y. Yang, M. T. Li et al., "Macrophage activation syndrome in systemic lupus erythematosus: a multicenter, case-control study in China," Clinical Rheumatology, 2017.

[8] G. S. Schulert and A. A. Grom, "Pathogenesis of macrophage activation syndrome and potential for cytokine- directed therapies," Annual Review of Medicine, vol. 66, no. 1, pp. 145-159, 2015.

[9] K. F. Wong, P. K. Hui, J. K. Chan, Y. W. Chan, and S. Y. Ha, "The acute lupus hemophagocytic syndrome," Annals of Internal Medicine, vol. 114, no. 5, pp. 387-390, 1991.

[10] R. Dhote, J. Simon, T. Papo et al., "Reactive hemophagocytic syndrome in adult systemic disease: report of twenty-six cases and literature review," Arthritis \& Rheumatism, vol. 49, no. 5, pp. 633-639, 2003.

[11] A. Ravelli, F. Minoia, S. Davì et al., "2016 Classification Criteria for Macrophage Activation Syndrome Complicating Systemic Juvenile Idiopathic Arthritis: a European League Against Rheumatism/American College of Rheumatology/Paediatric Rheumatology International Trials Organisation Collaborative Initiative," Annals of the Rheumatic Diseases, vol. 75, no. 3, pp. 481-489, 2016.

[12] S. S. Ahn, B. W. Yoo, S. M. Jung, S. W. Lee, Y. B. Park, and J. J. Song, "Application of the 2016 EULAR/ACR/PRINTO classification criteria for macrophage activation syndrome in patients with adult-onset Still disease," Journal of Rheumatology, vol. 44, no. 7, pp. 996-1003, 2017.

[13] S. Ahn, B. W. Yoo, S. M. Jung, S. W. Lee, Y. B. Park, and J. J. Song, "In-hospital mortality in febrile lupus patients based on 2016 EULAR/ACR/PRINTO classification criteria for macrophage activation syndrome," Seminars in Arthritis and Rheumatism, vol. 47, no. 2, pp. 216-221, 2017.

[14] M. Petri, A. M. Orbai, G. S. Alarcón et al., "Derivation and validation of the Systemic Lupus International Collaborating Clinics classification criteria for systemic lupus erythematosus," Arthritis \& Rheumatism, vol. 64, no. 8, pp. 2677-2686, 2012.

[15] F. Minoia, S. Davì, A. Horne et al., "Clinical features, treatment, and outcome of macrophage activation syndrome complicating systemic juvenile idiopathic arthritis: a multinational, multicenter study of 362 patients," Arthritis \& Rheumatology, vol. 66, no. 11, pp. 3160-3169, 2014.

[16] V. Boom, J. Anton, P. Lahdenne et al., "Evidence-based diagnosis and treatment of macrophage activation syndrome in systemic juvenile idiopathic arthritis," Pediatric Rheumatology, vol. 13, no. 1, p. 55, 2015.

[17] T. Henzan, K. Nagafuji, H. Tsukamoto et al., "Success with infliximab in treating refractory hemophagocytic lymphohistiocytosis," American Journal of Hematology, vol. 81, no. 1, pp. 59-61, 2006.

[18] M. Durand, Y. Troyanov, P. Laflamme, and G. Gregoire, "Macrophage activation syndrome treated with anakinra," Journal of Rheumatology, vol. 37, no. 4, pp. 879-880, 2010.

[19] T. Papo, M. H. Andre, Z. Amoura et al., "The spectrum of reactive hemophagocytic syndrome in systemic lupus erythematosus," Journal of Rheumatology, vol. 26, no. 4, pp. 927-930, 1999.

[20] T. Giese, M. Zeier, P. Schemmer et al., "Monitoring of NFATregulated gene expression in the peripheral blood of allograft recipients: a novel perspective toward individually optimized drug doses of cyclosporine A," Transplantation, vol. 77, no. 3 , pp. 339-344, 2004.

[21] A. Mak and N. Y. Kow, "The pathology of T cells in systemic lupus erythematosus," Journal of Immunology Research, vol. 2014, Article ID 419029, 8 pages, 2014.

[22] G. Moroni, A. Doria, and C. Ponticelli, "Cyclosporine (CsA) in lupus nephritis: assessing the evidence," Nephrology Dialysis Transplantation, vol. 24, no. 1, pp. 15-20, 2009.

[23] B. Griffiths, P. Emery, V. Ryan et al., "The BILAG multi-centre open randomized controlled trial comparing ciclosporin vs azathioprine in patients with severe SLE," Rheumatology, vol. 49, no. 4, pp. 723-732, 2010.

[24] N. Miyasaka, S. Kawai, and H. Hashimoto, "Efficacy and safety of tacrolimus for lupus nephritis: a placebo-controlled double-blind multicenter study," Modern Rheumatology, vol. 19, no. 6, pp. 606-615, 2009.

[25] T. Kraaij, O. W. Bredewold, S. Trompet, T. W. Huizinga et al., "TAC-TIC use of tacrolimus-based regimens in lupus nephritis," Lupus Science \& Medicine, vol. 3, no. 1, p. e000169, 2016. 


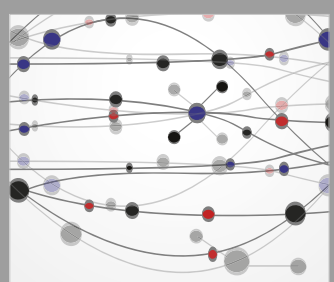

The Scientific World Journal
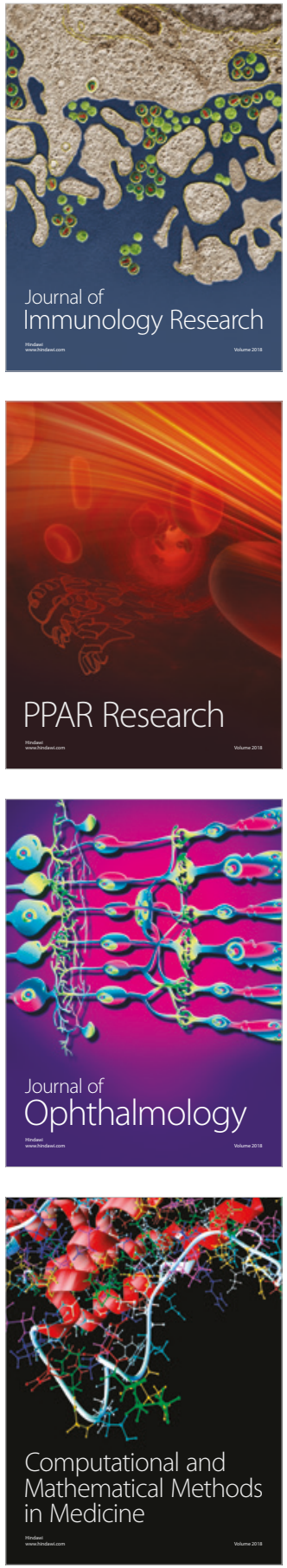

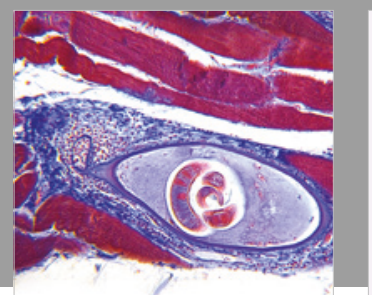

Gastroenterology Research and Practice

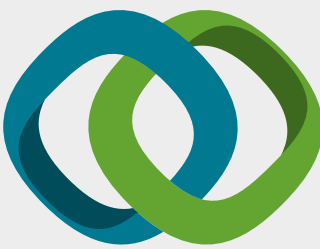

\section{Hindawi}

Submit your manuscripts at

www.hindawi.com
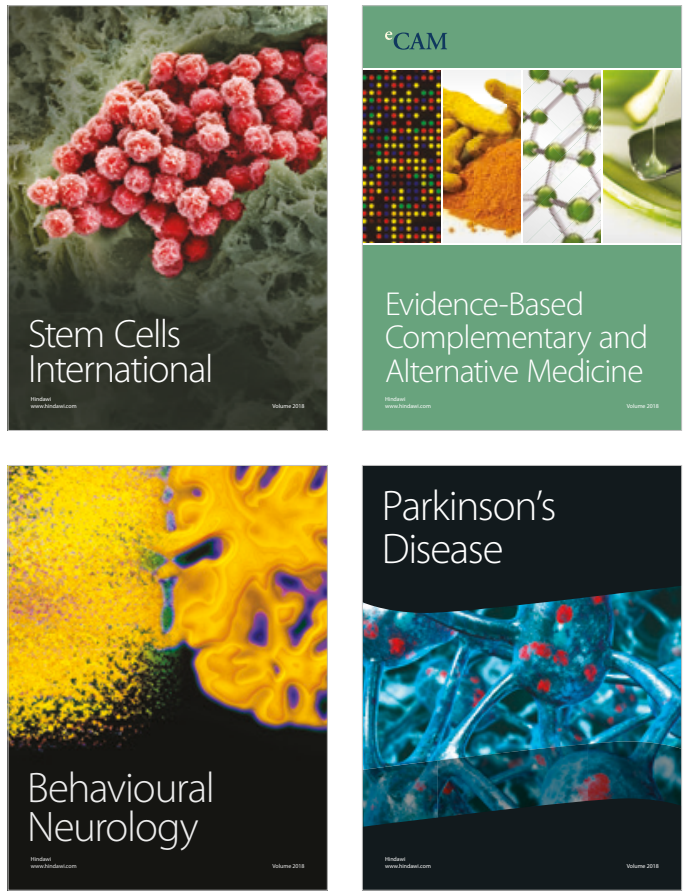

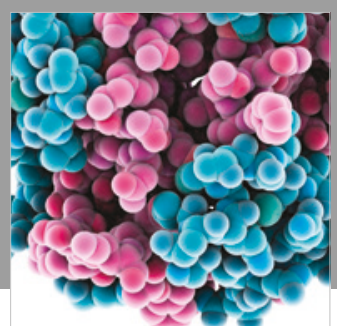

ournal of

Diabetes Research

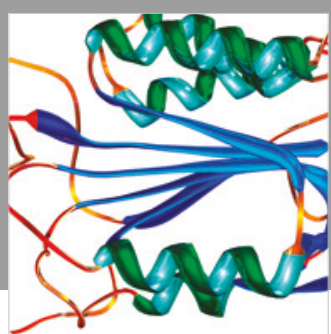

Disease Markers
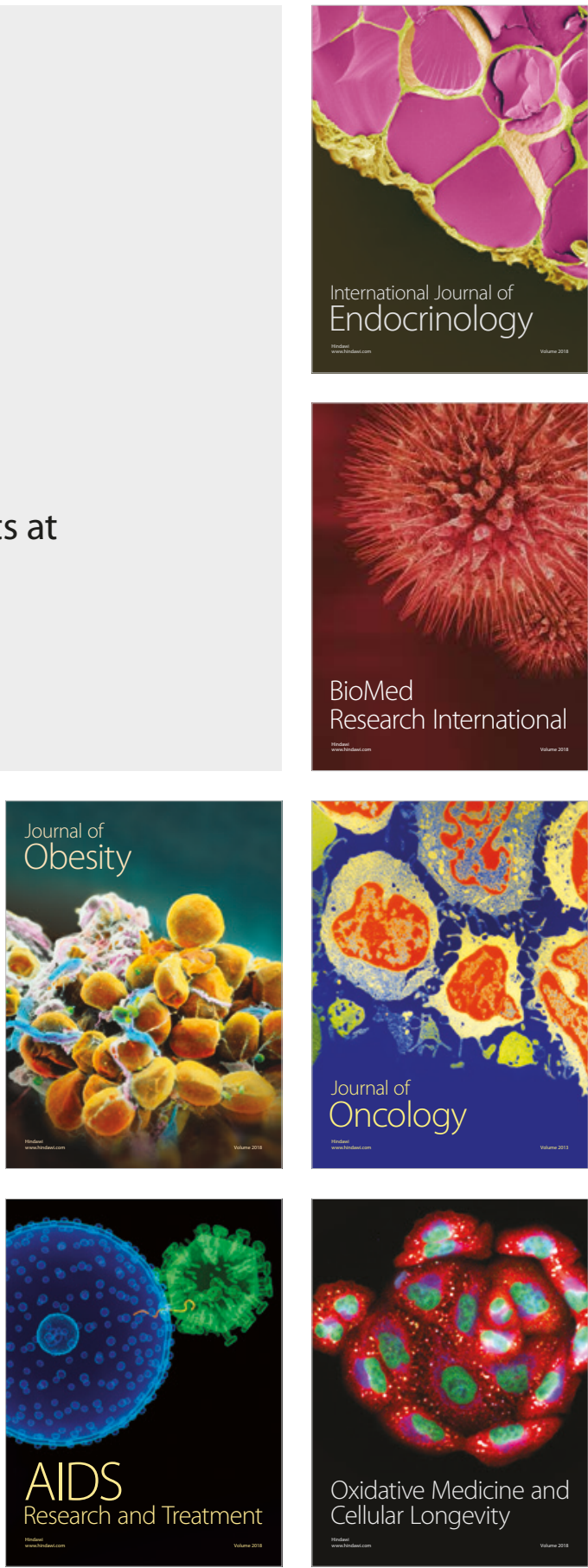